\title{
Quantitative Approach of the Ecological Response of Six Species Vascular Plants along an Altitudinal Gradient in Dongling Forest Mountain (Beijing)
}

\author{
MABESSIMO Cléoface Landry'
}

\author{
${ }^{1}$ School of Forestry, Beijing Forestry University, Beijing 100083, China
}

\begin{abstract}
In the current climate change crisis, lack of detailed climate knowledge of the behavior of species and the distribution of their abundance, can be an obstacle on sustainable biodiversity conservation. The goal of our paper is to study the ecological behavior of species along an altitudinal gradient in order to predict their abundance. Six species of vascular plants, sampled in Dongling forest have been the subject of this study. The use of the Gaussian regression allowed calculating three ecological parameters including the optimum, tolerance and maximum, from which six distribution models have been designed; the expected model was the bell curve (Gaussian curve). Among the six species sampled, only Quercus liaotungensis reacted with the expected response to the abundance of its plants. Moreover, the species Acer mono, Betula platyphylla, Juglan mandshurica and Pinus tabuliformis have reacted with answers of parabola-shaped curves; However, Deutzia grandiflora was the only species to react with a totally different response of two other groups of species curve. However, the calculated ecological parameters allowed obtaining an equation for prediction of abundance for each species. Although species response curves to a gradient can take many forms, our results have highlighted that only one species reacts with the expected response. In view of the fragility of China's natural ecosystems, it is urgent that similar studies, on a large scale, can be conducted in order to determine the ecological behavior of a large number of species, to strengthen their capacity for management and conservation.
\end{abstract}

Keywords: Vascular Plants, Abundance, Models, Prediction, Dongling

\section{Introduction}

Resource management and forest biodiversity may know profound changes in the light of current climate change, which will force the species to moving their ranges (Dominic Chambers, 2011). Some studies have already addressed the issues of distribution and abundance of species prediction (Beetling 1993, Gates et al., 1993, Pakeman, RJ et al., 1996), to show how it is very important to try to understand and target the ecological factors that currently govern species off again.

However, different work in the field of ecology, have played and continued to play a large role in finding solutions to problems related to distribution and prediction of species abundance. We can mention the work on the concept of the ecological niche, that have made their contributions in understanding the relationships between species and their environment; we can find also, the studies made by Chase and Leibold (2003), Austin (1985), Kearney (2006) Daget et Godron (1982) and those of Christophe Coudun (2005). These works were much more based on design models to explain more, the behavior of a species in a given environment. Modelling the ecological response of a species along a given environmental gradient, with applications in predicting species distribution in the present case of climate change (Guisan et al. 1998), was the one way to determine quantitatively the niche of a species (Coudun 2005).

With national coverage of approximately $22 \%$, the Chinese forest ecosystems are of particular importance in the provision of various products and environmental services to the population (JinzhuoWu

This article is published under the terms of the Creative Commons Attribution License 4.0 Author(s) retain the copyright of this article. Publication rights with Alkhaer Publications. Published at: http://www.ijsciences.com/pub/issue/2015-04/

Article Number: V420150405; Online ISSN: 2305-3925; Print ISSN: 2410-4477 
\& al., 2013). However, in 2008, during the fourth national report, the Chinese Ministry of Environment and Protection on the implementation of the Convention on Biological Diversity, call public attention to the threats faced by species that populated these ecosystems, of which approximately $41 \%$ are plants. To these must be added, climate change, industrialization, rapid urbanization, loss of biodiversity (JinzhuoWu \& al., 2013), forest fires, the loss and fragmentation of habitat, environmental pollution, that will increasingly fragile natural ecosystems of the China. This is why special attention must be paid to the behaviour of forest species, because, if a species may tolerate or even take advantage of the deterioration of its environment, but a disruption, same, very limited can lead to its extinction. The objective of this paper is performing a quantitative approach to the ecological response of six species of vascular plants sampled in the forest ecosystem of Dongling, around Beijing.

\section{Method}

\subsection{Study area}

The Dongling Forest ecosystem is located in southwest of Beijing, between $115^{\circ} 26^{\prime} \mathrm{E}$ and $40^{\circ} 00^{\prime}$ N (Wu Xiao-Pu et al. 2002, Hai-Bao Ren et al. 2006). The forest of Dongling constitutes an important ecological barrier that protects the inhabitants of Beijing against the storms of dust from the western regions. Dongling enjoys a continental monsoon climate temperate. This then allows him to know the cold and dry winters and hot summers; the average annual temperature varies around of $4.8,7{ }^{\circ} \mathrm{C}$ with rainfall, annual average of 500-650 mm (Ji-hua Hou et al. 2006, JIN-TUN ZHANG et al. 2013). From the values of its three parameters, and knowing the value of $x$, it is easy to determine the value of $z$, which is the predicted abundance. For this work, all the calculations and the models were realized with the PAST software (Hammer et al., 2001). Its soils of type cinnamon soil, mountain cinnamon soil, brown forest soil and mountain meadow soil (JIN - TUN ZHANG et al. 2013), are pushed vegetation type warm temperate deciduous broad-leaved forest (Hai Bao Ren et al. 2006), dominated by $Q$. liaotungensis
(Ji-hua Hou et al., 2006); However, it can meet the scrub lands secondary between 800 to $1,200 \mathrm{~m}$, secondary forests of 1000 to $1800 \mathrm{~m}$ and mountain meadows has $1600 \mathrm{~m}$ to the top of the mountain. Despite the altitude that varies between 689.6-2303 m (Hai - Bao Ren et al. 2006, this ecosystem offers to residents of Beijing, of best parts of recreation during the summer.

\subsection{Data collection}

The data were gathered in July 2013 and were recorded at different levels including the sampling unit (plot), which is the highest level, and subunits of smaller sizes (plots), bounded on the inside of the unit sampling. A sample unit corresponds to a plot of $400 \mathrm{~m}^{2}(20 \mathrm{~m} \times 20 \mathrm{~m})$ within which to cut a group of 16 contiguous plots $(5 \mathrm{~m} \times 5 \mathrm{~m}$ each) numbered 1 to 16 in the direction of magnetic north. Before a species inventory for each parcel, we had taken its geographic coordinates, altitude, gradient and the density of the canopy. In a given plot, all woody species were identified and counted and, a total of five units were sampled, and allowed to know the floristic composition of the study area.

\subsection{Data analysis}

Theoretically, the response of a species to an environmental gradient, is represented by a bellshaped curve, the center represent the ecological optimum for the species and spreading tolerance characteristic of the species for this environmental variable. To build the model distribution of species abundance, the equation of the Gaussian curve was used. This equation is defined as follows:

$$
z=m \times e^{\left[-\frac{1}{2}(x-u)^{2} /(t)^{2}\right]}
$$

Where $\mathrm{u}$ is a optimum of the species on the gradient; $\mathrm{m}$, the maximum of abundance observed at the optimum, and t tolerance or ecological amplitude of the species (ter Braak, C.J.F \& h. van Dam, 1989); either $\mathrm{x}$ an position on the gradient, and $\mathrm{z}$ the value of abundance predicted. From a linear regression type:

$$
y=a_{0}+a_{1} x+a_{2} x^{2}
$$

We calculated the optimum, tolerance and the maximum, taking account of the relationships in Table 1.

Table 1. Species biological parameters formulas.

\begin{tabular}{cc}
\hline & Computation Formula \\
\hline Optimum & $u=-\frac{a_{1}}{2 a_{2}}$
\end{tabular}

(2.3.3)

Tolerance $\quad t=\frac{1}{\left(-2 a_{2}\right)^{\frac{1}{2}}}$

(2.3.4) 
Quantitative Approach of the Ecological Response of Six Species Vascular Plants along an Altitudinal Gradient in Dongling Forest Mountain (Beijing)

\begin{tabular}{ll}
\hline $\begin{array}{l}\text { Maximum } \\
(2.3 .5)\end{array}$ & $m=\exp \left(a_{0}+a_{1} u+a_{2} u^{2}\right)$ \\
\hline
\end{tabular}

\section{Results}

3.1 Distribution models

Six models, showing the distribution of the species according to the altitude (figure 1) have been obtained. Among the six models, Q. liaotungensis (fig. f), reacted with a Gaussian-shaped response to the abundance of its plants; the probability of its occurrence (optimum) is located approximately 1348, $43 \mathrm{~m}$ altitude with a maximum of 45 plants observed. The species A. mono (fig. a), B. platyphylla (fig. b), $J$. mandshurica (fig. d) and P. tabuliformis (fig. e), are
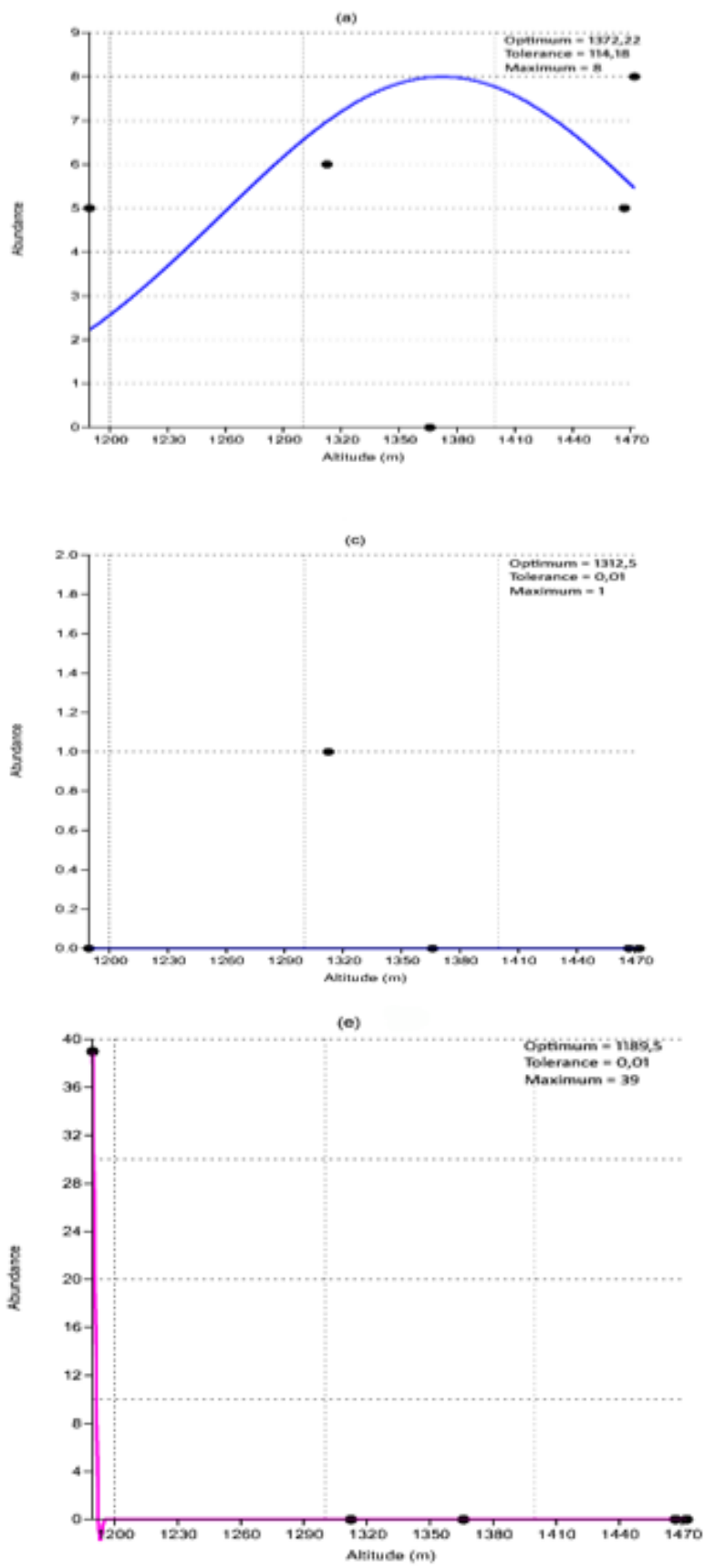

reacts, each, with a parabola-shaped response curve to the abundance of their plants. Their optimum, are respectively at $1372,22 \mathrm{~m}, 1469,22 \mathrm{~m}, \quad 1248,33 \mathrm{~m}$ and $1189,5 \mathrm{~m}$; the maximum of plants corresponding to these optimum are respectively, 8 plants for A. mono, 19 for B. platyphylla, 1 for D. grandifolia, 4 plants for J. mandshurica, 39 for P. tabuliformis. However, D. grandifolia, has have a curved shape that resembles neither a bell curve or in the form of a parabola.
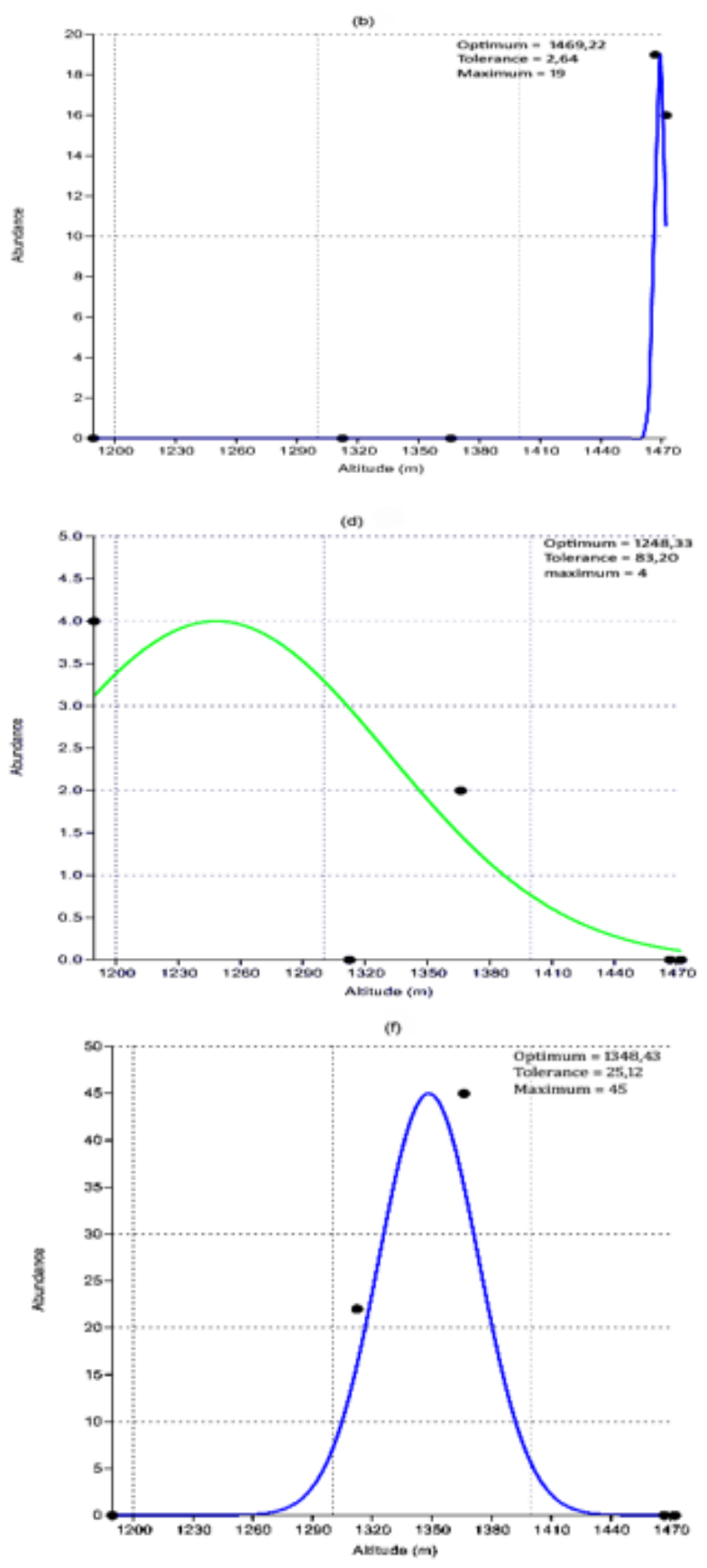
Figure 1. Response curves along an altitudinal gradient of six species sampled in Dongling forest: (a): A. mono; (b): B. platyphylla; (c): D. grandifolia; (d): J. mandshurica; (e): P. tabuliformis; (f): $Q$. liaotungensis.

\subsection{Species abundance prediction}

The distribution of species, according to the different altitudes, identifies four groups: group formed by $A$. mono, D. grandifolia and $Q$. liaotungensis, belong to the group of plants can suffer from stress when they find themselves apart from an average maximum altitude of about $1344 \mathrm{~m}$. However, Q. liatungensis present better tolerance compared with the two other species of the groups. The second group, formed by $B$. platyphylla, J. mandshurica and P. tabuliformis, can see their reduced performance, when they find a mean optimal altitudes, respectively $1400 \mathrm{~m}$ for $B$. platyphylla, $1200 \mathrm{~m}$ for J. mandshurica and $1,100 \mathrm{~m}$ for P. tabuliformis. However, the species $J$. mandshurica, have a good tolerances $(\mathrm{t}=83.20)$ compared to $B$. platyphylla $(\mathrm{t}=2.64)$ and $\mathrm{P}$. tabuliformis $(\mathrm{t}=0.01)$. The Gaussian regression provided the optimum, tolerance and maximum for each of the six species of plants. The combination of these factors has allowed getting six equations models (Table 2), corresponding to the six sampled species, to predict the abundance of species in the site Dongling.

Table 2. Models of abundance prediction equations obtained from the ecological parameters of the species.

\begin{tabular}{|c|c|c|c|c|c|}
\hline Species & $\begin{array}{l}\text { Optimum } \\
\text { (u)) }\end{array}$ & $\begin{array}{c}\text { Tolerance } \\
\text { (t) }\end{array}$ & $\begin{array}{l}\text { Maximum } \\
\text { (m) }\end{array}$ & Equation Model & \\
\hline Acer mono Maxim. & 1372,22 & 114,18 & 8 & $z=8 \times e^{\frac{\left[-\frac{1}{2}(x-1372,22)^{2}\right]}{(114,18)^{2}}}$ & (3.2.1) \\
\hline $\begin{array}{l}\text { Betula platyphylla } \\
\text { Suk. }\end{array}$ & 1469,22 & 2,64 & 19 & $z=19 \times e^{\frac{\left[-\frac{1}{2}(x-1469,22)^{2}\right]}{(2,64)^{2}}}$ & $(3.2 .2)$ \\
\hline Deutzia grandifolia & 1312,5 & 0,01 & 1 & $z=e^{\frac{\left[-\frac{1}{2}(x-13125)^{2}\right]}{(0,01)^{2}}}$ & $(3.2 .3)$ \\
\hline $\begin{array}{l}\text { Juglans mandshurica } \\
\text { Maxim. }\end{array}$ & 1248,33 & 83,20 & 4 & $z=4 \times e^{\frac{\left[-\frac{1}{2}(x-1248,33)^{2}\right]}{(83,20)^{2}}}$ & (3.2.4) \\
\hline Pinus tabuliformis & 1189,5 & 0,01 & 39 & $z=39 \times e^{\frac{\left[-\frac{1}{2}(x-1189,5)^{2}\right]}{(0,01)^{2}}}$ & $(3.2 .5)$ \\
\hline $\begin{array}{l}\text { Quercus liaotungensis } \\
\text { Koidz }\end{array}$ & 1348,43 & 25,12 & 45 & $z=45 \times e^{\frac{\left[-\frac{1}{2}(x-1348,43)^{2}\right]}{(25,12)^{2}}}$ & (3.2.6) \\
\hline
\end{tabular}

\section{Discussion and conclusion}

The results that we obtained are consistent with the hypothesis posed. Much work on modelling the distribution of species abundance, using presence/absence of a species, however we used the abundance data and only ecological variable, on which the Gaussian regression was applied. For each sampled species, its ecological response curve has been drawn. When we compare this work to other previous work on the ecology distribution models (Rosalind Van Couwenberghe 2011, Christophe Coudun 2005), each curve provides the variable value for which the probability of finding the species maximum (optimum), tolerance is a range of 
environments in which the species can survive, and the maximum that characterizes the maximum frequency of the species along the gradient.

There are several methods of regression using the statistical method to analyze the dependencies between a dependent variable and one or more independent variables, quantitative and qualitative, as the case generalized linear models (Harrell, 2001). Even if today there are very efficient regression methods (Austin et al., 1984), the example of logistic regression, we find a better, simple and very practical, Gaussian regression made with the PAST software (Hammer et al., 2001).

Although the mere use of the abundance of species, without their processing binary data (presence / absence) could lead to consistent results we share the idea that Christophe Coudun (2005), like many other authors think that to link the ecological behavior of forest species measured ecological factors, will increase our knowledge of the species autoecology (Schaffers and Sykora 2000, Wamelink et al., 2002) quoted by Christophe Coudun (2005). The ecological behavior of eight species in four regions along a gradient from central Europe to northern Europe was studied by Diekmann and Lawesson (1999); the results of their work has shown that some species could be of optimum ecological changes in different regions; So we believe that our work should be as interesting if we had made in several areas. However, it would be better to make a second work that can be carried by comparing examples of our search with the existing literature.

We studied six species and model their behavior along an altitudinal gradient. We found and show a single species, Q. liaotungensis had a normal distribution (Rosalind Van Couwenberghe 2011), and consistent with the Gaussian distribution, which is the expected response. However, six species reacts with response curves parabolic, and one species, D. grandifolia has a distribution or close to a normal distribution model or a linear distribution model. DAGET J., C. and C. LECORDIER LEVEQUE (1972), studying the nomocenose and applications in ecology, says that often have a sample or set of samples lead to distributions of abundances that approach nor a lognormal model or a log-linear model; we think, for this case, the sample size may be influence on the different types of model. Exceptional cases observed in D. grandiflora, can be explained by different biotic contexts in different altitude levels. This trend observed higher abundance of different altitude levels may be due to competition in the environment. Several abundance prediction works species have been already conducted (Javier Sawchik et al., 2005) using the Gaussian regression, with the aim of obtaining a prediction model. For this paper, we also got six prediction equations by combining the optimum, and maximum tolerance, to predict the abundance of six plant species when you know the $\mathrm{x}$ position of the species in the gradient.

Our study did not address all the common vascular species of the Beijing forests. However, the results we have presented could not be observed if we had studied all species presented in this ecosystem. Moreover, we have not considered other parameters, for example the influence of competitive conditions on the ecological response of species. We hope that further studies are planned so that ecological theory can provide more information about the distribution and abundance of species prediction Dongling.

To conclude this work, we have just analyzed the ecological behavior of six species of a forest ecosystem in southeastern Beijing; the chosen methods enable us to build six models of abundance distribution and six prediction equations abundance of each of its species. Certainly, the experiment was focused on a small number of sample, but constitutes a source of information on which to launch major work on the deep comprehension the ecological behavior of the species. We don't work on a database, from which we could select statements; but we perform field measurements to obtain the data. The number of plots and the sample size can't inform about all the main factors that affect the survival or development of species in the Beijing area. But this work is important, because it already informs the behavior of six species and provides research of the figures that relate to ecological parameters and then, and offers at the same time relationships templates that can be used to calculate a predictive value of species abundance. The distribution of species on the five stages of vegetation of the forest of Dongling seems irregular. We therefore believe that the modeling of the distribution of the species is a strong argument to show that environmental factors may account for over $50 \%$ of presences and absences of species along an ecological gradient. With the advent of climate change and its adverse effects on the trees of the forest, paper is an opportunity to strengthen the conservation of plant species in China.

\section{REFERENCE}

I. Austin, M. P. Continuum concept, ordination methods and niche theory. Annual Review of Ecology and Systematics, 1985, 16, 39-61. http://dx.doi.org/10.1146/annurev.ecolsys.16.1.39

II. Austin, M. P., R. B. Cunningham et P. M. Fleming, New approaches to direct gradient analysis using environmental scalars et statistical curve-fitting procedures. Vegetation, 1984, 55, 11-27. http://dx.doi.org/10.1007/bf00039976

III. Beerling, D.J., The impact of temperature on the northern distribution limits of the introduced species 
Fallopia japonica and Impatiens glandulifera in northwest Europe. Journal of Biogeography, 1993, 20: 4553. http://dx.doi.org/10.2307/2845738

IV. Chase, J.M. \& Leibold, M.A., Ecological Niches. University of Chicago Press, Chicago, IL, 2003.

V. Christophe Coudun, Approche quantitative de la réponse écologique des espèces végétales forestières à l'échelle de la France. Ecologie, environnement. ENGREF (AgroParisTech), 2005, French. <tel00011330>

VI. Daget, P. et M. Godron, Analyse fréquentielle de l'écologie des espèces dans les communautés. Collection d'écologie, 18, Masson, Paris, 1982. http://dx.doi.org/10.2307/2530777

VII. Diekmann, M. et J. E. Lawesson, Shifts in ecological behaviour of herbaceous forest species along a transect from northern central to north Europe. Folia Geobotanica, $\quad 1999, \quad 34, \quad 127-141$. http://dx.doi.org/10.1007/bf02803080

VIII. Dominic Chambers, Challenges in modeling the abundance of 105 tree species in eastern North America for climate change research. Department of Plant Science and McGill School of Environment Macdonald Campus of McGill University Ste-Anne-de-Bellevue, Quebec, Canada, 2011.

IX. Gates, S., Gibbons, D.W., Lack, P.C. \& Fuller, R.J., Declining farmland bird species: modelling geographical patterns of abundance in Britain. In "Large-Scale Ecology and Conservation Biology", Edwards, P.J, May, R.M. \& Webb, N.R. (Eds), Blackwell Scientific Publications, 1993, pp 153-177.

X. Hammer, Ø., Harper, D.A.T., and P. D. Ryan, PAST: Paleontological Statistics Software Package

XI. for Education and Data Analysis. Palaeontologia Electronica, 2001, 4(1): 9pp

XII. Hai-Bao Ren, Shu-Kui Niu, Lin-Yan Zhang, Ke-Ping Ma, Distribution of Vascular Plant Species Richness along an Elevational Gradient in the Dongling Mountains, Beijing, China. Journal of Integrative Plant Biology, 2006, 48 (2): 153-160. http://dx.doi.org/10.1111/j.1744-7909.2006.00153.x

XIII. J. DAGET, C. LECORDIER et C. LEVEQUE, Notion de nomocénose : Ses applications en écologie. Bull. SOC. Ecol., 1972, t. III, 4, p. 448-462.

XIV. Ji-hua Hou, Xiang-cheng Mi, Can-ran Liu, Ke-ping Ma, Tree competition and species coexistence in a Quercus-
Betula forest in the Dongling Mountains in northern China. ACTA OECOLO G ICA 30 (2006) 117-125. http://dx.doi.org/10.1016/j.actao.2005.10.002

XV. JIN-TUN ZHANG, BIN ZHANG, MIN LI AND XUNZHI ZHU (2013). Functional diversity and conservation of Phellodendron amurensis communities in the Mountain of Beijing, China. Botanical Sciences 91 (4): 505-513.

XVI. Javier Sawchik, Marc Dufrêne and Philippe Lebrun, Distribution patterns and indicator species of butterfly assemblages of wet meadows in southern Belgium. Belg. J. Zool., 2005, 135 (1): 43-52.

XVII. JinzhuoWu, Wenshu Lin, Xuanyi Peng, and Weiguo Liu, A Review of Forest Resources and Forest Biodiversity Evaluation System in China. International Journal of Forestry Research. Volume 2013, Article ID 396345, 7 pages. http://dx.doi.org/10.1155/2013/396345

XVIII. Kearney, M., Habitat, environment and niche: what are we modelling? Oikos, 2006. 115, 186-191. http://dx.doi.org/10.1111/j.2006.0030-1299.14908.x

XIX. Pakeman, R.J. \& Marrs, R.H., The effect of climate change on the growth of bracken (Pteridilium aqualinum) in Britain. Journal of Applied Ecology, 1996, 33: 561-575. http://dx.doi.org/10.2307/2404985

XX. Rosalinde Van Couwenberghe, Effets des facteurs environnementaux sur la distribution et l'abondance des espèces végétales forestières aux échelles locales et régionales. Ecosystème. (AgroParisTech.), 2005, French. 〈NNT: 2011AGPT0016〉. 〈pastel-00604628>.

XXI. Schaffers, A. P. et K. V. Sykora, Reliability of Ellenberg indicator values for moisture, nitrogen et soil reaction: A comparison with field measurements. Journal of Vegetation Science, 2000, 11, 225-244. http://dx.doi.org/10.2307/3236802

XXII. Wamelink, G. W. W., V. Joosten, H. F. Van Dobben et F. Berendse, Validity of Ellenberg indicator values judged from physicochemical field measurements. Journal of Vegetation Science, 2000, 13, 269-278. http://dx.doi.org/10.1111/j.1654-1103.2002.tb02047.x

XXIII. Wu Xiao-Pu, Zheng Yu, MA Ke-Ping. Population distribution and dynams of Quercus liaotungensis, Fraxinus rhynchophylla and Acer mono in Dongling Mountain, Beijing. Acta Botanica Sinica 2002, 44(2): 212-223. 